\title{
O LEITOR ADOLESCENTE EM QUERIDA
}

Gisela Johann

johanngisela@gyahoo.com.br Universidade Estadual do Oeste do Paraná, Cascavel, Brasil.

\section{RESUMO}

Há 42 anos a Fundação Nacional do Livro Infantil e Juvenil - FNLIJ seleciona obras que são merecedoras do Selo Altamente Recomendável. A escritora Lygia Bojunga, de forma recorrente, tem recebido a láurea. Sua mais recente obra premiada foi Querida, publicada em 2009 e premiada em 2010. O presente trabalho busca identificar em que medida a obra Querida (2009) dialoga com o leitor, considerando-o pertencente à faixa etária cuja obra foi premiada, aos adolescentes. De fato, para identificar tais aspectos de diálogo (leitor-livro), este trabalho considerará a literatura como uma representação simbólica e imaginária das relações sociais, amparando-se nos conceitos e discussões da Sociologia da Leitura, bem como, da estética da recepção, a partir daquilo que a obra Querida pressupõe de seu leitor modelo, apontando o que este deve ser capaz de entender para preencher os vazios do texto. Dessa forma, este estudo procura indicar, também, a relevância dos aspectos socioculturais imbricados na construção deste leitor modelo.
\end{abstract}

PALAVRAS-CHAVE: Querida. Leitor. Lygia Bojunga. 


\section{INTRODUÇÃO}

Querida (BOJUNGA, 2009) foi uma das obras premiadas em 2010 pela Fundação Nacional do Livro Infantil e Juvenil (FNLIJ) com o selo de Altamente Recomendável. Este selo pode ampliar a visibilidade da obra, proporcionando-lhe aumento nas vendas, a procura no mercado específico como livrarias e bibliotecas, até a sua finalidade: a leitura feita e concretizada pelos adolescentes.

Desse modo, a Fundação Nacional do Livro Infantil e Juvenil (FNLIJ) pode ser considerada fomentadora de um grupo seleto de livros destinados aos adolescentes e às crianças, de maneira geral. Mas, o que há em Querida (2009) para que a FNLIJ considerasse esta obra de interesse aos adolescentes e porque seria recomendável sua leitura?

É a particularidade na forma de narrar aliada ao que se espera do leitor que permite a interação entre leitor e texto. Conforme Hunt (2010), a interação entre texto e leitor exige deste toda a sua concentração e que ele acione todas as suas experiências culturais, sociais e psicológicas.

Deste modo, para que haja diálogo entre um texto e seu leitor é necessário que este se perceba dentro do contexto, ou ainda, entenda esse universo ficcional de maneira a completar as lacunas textuais. As lacunas de um texto, bem como a capacidade de compreendê-las são explicadas por Umberto Eco (1994) através do conceito de leitor modelo. Para este autor, o leitor modelo não é o empírico, pois os leitores empíricos podem ler de diversas formas, sem uma lei que os possa regê-los, cada um irá ler a partir de suas próprias experiências. À vista disto, leitor modelo é aquele pensado pelo autor, disposto a acompanhar o texto tal qual um expectador de um filme, em que o diretor espera determinadas reações do seu público: "Eu chamo de leitor modelo uma espécie de tipo ideal que o texto não só prevê como colaborador, mas ainda procura criar" (ECO, 1994, p. 15).

(Isto posto, esperar que o leitor caracterize os personagens é uma das chaves que movimentam a narrativa, pois, segundo Eco (1994) "O texto é uma máquina preguiçosa que espera muita colaboração da parte do leitor" (p. 34).) Dessa maneira, o leitor estaria entrando no jogo, no processo de aquisição daquilo que está sendo lido.

Assim, esta análise busca apresentar os aspectos literários nas formas de narrar em Querida (2009) que se engendram para construir uma narrativa que associa temáticas comuns aos adolescentes aos questionamentos do processo de transição entre o pensar adulto e o pensar criança.

\section{O UNIVERSO DO ADOLESCENTE}

O universo real do adolescente contemporâneo está inserido em uma sociedade que outrora se pautava nas regras ditadas pela Igreja, Estado, Escola e a Família tradicional. Não obstante, há mudança naquilo que ditaria as regras na contemporaneidade, Bauman (2001) a nomeia como modernidade líquida. Para esse autor, a sociedade, dentro desse modelo, estaria sendo motivada e impulsionada pelo consumo. Desta maneira, as instituições regulamentadoras transitariam para a ciência e a moda. A ciência explicaria o mundo e as formas de 
bem viver, pautadas no corpo saudável, cientificamente comprovado com exercícios físicos e alimentação rigorosamente espiada pela medicina. A moda, por sua vez, seria a grande incentivadora da exibição desse corpo consumidor, provendo mudanças rápidas de modelos de vestimenta e tecnologia, impulsionando o consumo exacerbado.

Dentro desse contexto, a família tradicional (pai, mãe e filhos) não ocuparia mais lugar de formadora de opinião, o que poderia ocasionar ao adolescente contemporâneo uma crise sobre as funções da família e escola. Estas tinham a incumbência de refrear e regulamentar os seus impulsos e desejos, em nome da estabilidade e busca de um espaço fixo, assim que esse adolescente tornava-se adulto. Contemporaneamente, o que se apresenta ao jovem é a efemeridade como solução. O amor é líquido, pois se liquefaz no desejo, no impulso, acelerando os relacionamentos a não terem continuidade e, tampouco, estabilidade. Há uma busca constante pela satisfação dos desejos, que podem ser materiais ou físicos.

Nesse viés, a Arte, por conseguinte a Literatura, se constrói e desconstrói, buscando ressignificar o que já está produzido. Fredric Jameson (1985) explica que a Arte apresenta uma emergência atrelada ao presente perpétuo que a sociedade capitalista multinacional promove. Essa promoção tende a eliminar o passado em uma perpétua mudança que apaga as tradições sociais anteriores.

Jameson ressalta, ainda, que a Arte estaria a serviço do consumo, ou seja, da lógica capitalista, mas, o próprio autor questiona "se também não existe uma forma de resistência a essa lógica”. (JAMESON, 1985, p.26).

A obra literária pode, então, subverter a sua lógica e o primeiro passo para entender como esse processo se dá é entender quem é o leitor da obra.

\section{O DESTINATÁRIO DA LITERATURA JUVENIL E QUERIDA}

A narrativa começa com o personagem já adulto lendo a notícia de que a artista Ella faleceu, ele então reconhece a mulher e começa recordar de um episódio da infância que marcou profundamente sua vida e o fez conhecer uma pessoa muito especial, seu tio.

Assim, o episódio inicia com o protagonista, um menino de dez anos cujo nome é Pollux. Mas, há também um importante personagem que divide a cena com o menino, o Pacífico, trata-se do tio do garoto, que há muito tempo não tem contato com a família. A narrativa fala, então, da jornada do Pollux para encontrar seu tio e conta como se deu esse encontro que aproximou as duas gerações em torno de um sentimento em comum: o ciúme.

Este ciúme é quem impulsiona Pollux a fugir de casa e procurar o tio, pois, após a morte do pai, a mãe casa-se novamente, o que faz o garoto imaginar que estaria perdendo a sua mãe para outro homem, que não era seu pai. Ele tenta de muitas maneiras fazer com que a mãe não goste do marido, mente e constrói histórias que apresentam o padrasto como um vilão. Mas, todas as suas mentiras não lhe dão triunfo de separar o padrasto Roberto da sua mãe, desta forma, o menino resolve fugir de casa como vingança, para fazer com que a mãe sofra a ausência dele. Busca então encontrar o seu tio Pacífico e começa a conhecer um 
pouco mais sobre esse ente da família que se distanciara de todos em nome da devoção por uma mulher, Ella. O tio mora em um retiro, afastado da cidade e vive nesse lugar servindo a mulher que sempre amou. Nesse lugar, Pollux compreende seus sentimentos com ajuda de Ella e Pacífico, resolve voltar pra casa e encarar os desafios que a vida estava the proporcionando.

A partir do enredo de Querida, essa análise fixar-se-á nos aspectos da narrativa que a tornam especialmente recomendada ao público jovem, e ainda, enfatizar como o leitor pode perceber tais aspectos e o que estes podem interferir na sua formação leitora.

O primeiro aspecto da obra que se pode destacar como elo entre o leitor e o livro é a forma de narrar de Lygia Bojunga (2009), os diálogos e as formações lexicais aproximadas da linguagem oral, tão comum entre os adolescentes, permitem a aproximação desse leitor ao texto: "- Pollux? O Pollux fez que sim. que Pollux? - O Pollux, ué.” (BOJUNGA, 2009, p. 14).

Sobre a forma de narrar de Lygia Bojunga é importante destacar que ao passo do diálogo a autora não descreve as características físicas dos personagens, ficando a cargo do leitor essa função. Portanto, Querida se afina ao leitor exatamente naquilo que lhe é mais volátil, a sua subjetividade. Assim, é exatamente esta não demarcação de características físicas que concretizam as inúmeras possibilidades de identificação com o leitor. O texto não fala a cor do cabelo do Pollux, muito menos descreve o tom da sua pele. Bojunga (2009) não reifica os estereótipos sociais, pelo contrário, deixa o leitor construir seu personagem, direcionado apenas naquilo que lhe é fundamental, a personalidade embutida no jeito de falar de cada personagem.

Cabe salientar que o leitor da literatura juvenil é típico da sociedade atual, dentro da sua inconstância, buscando informações a passos acelerados. Colomer (2003) explica que a literatura juvenil adéqua-se as características do seu público, definindo o leitor implícito dentro de uma série de características as quais convém apresentar. Primeiro mostra-se um leitor próprio da sociedade atual, assim, os textos que the são dirigidos refletem as mudanças sociais e educativas da sociedade pós-industrial e democrática. Isto proporciona aos textos modificações significativas, revelando uma narrativa que se preocupa com os temas que são relevantes atualmente, tanto na descrição do mundo como nos valores por este proposto. Assim, a autora ainda enfatiza:

O destinatário da literatura infantil e juvenil de qualidade pode definir-se como um leitor criança ou adolescente, que aprende socialmente e a quem se dirige textos que pretendem favorecer sua educação social através de uma proposta de valores, de modelos de relação social e de interpretação ordenada do mundo. (COLOMER, 2003, p. 173).

Partindo destas considerações pode-se dizer que Querida mostra-se como uma narrativa que se afina com os temas e as características explicadas por Colomer (2003) sobre o leitor implícito da literatura juvenil. Assim, se este leitor está ambientalizado na sociedade atual convém lembrar que os modelos e estruturas familiares mudaram, e não há mais a regra absoluta da família nuclear, formada pela mãe, pai e os filhos. Desta maneira, no trecho a seguir, nota-se esta evidência da formação familiar, que destoa da tradicional: “(...) Eu conheço meu 
filho mais do que a mim mesma. Foi só eu me casar com o Roberto que o Pollux mergulhou de cabeça numa crise de ciúme..." (BOJUNGA, 2009, p. 98-99). Em Querida, então, a família apresentada ao leitor definiu-se em mãe, filho e padrasto. Deste modo, observa-se na narrativa de Lygia Bojunga (2009) como a figura do padrasto pode manifestar-se dentro da família contemporânea:

(...) O Roberto já não sabe mais o que fazer para ganhar o amor de Pollux (...) O Roberto é um vegetariano convicto porque não aguenta pactuar com a morte de nenhum bicho, nem que seja uma miserável galinha ou um infeliz caranguejo; é uma pessoa totalmente voltada para a construção de um mundo de paz. (BOJUNGA, 2009, p. 99-100)

Assim, tal citação mostra um aspecto que pode aproximar o leitor daquilo que ele vê e vive, pois, a literatura juvenil contemporânea de qualidade não pretende se destacar pela reificação de estereótipos familiares e sim, apresentar aquilo que a sociedade vive, sem julgamentos de superioridade ou inferioridade, quebrando o paradigma conservador de que um padrasto é sempre uma figura maligna aos enteados.

Outro traço do leitor implícito explicado por Colomer (2003) refere-se ao leitor que vive na inconstância do crescimento físico e psicológico, ou seja, a adolescência: "um leitor cuja idade aumenta que amplia progressivamente suas possibilidades de compreensão do mundo. (...) a quem se dirige textos que deveriam diferenciar segundo as características psicológicas da idade." (COLOMER, 2003, p.175).

Para Carrano (2005), a juventude atual não se prende mais aos conflitos a respeito de ideologias sociais deslocadas da sua realidade, outras questões parecem ser mais emergenciais à juventude:

\begin{abstract}
A juventude é uma categoria sociológica inventada pelos adultos; entretanto, torna-se cada vez mais difícil defini-la. Quando muito, podemos elaborar provisórios mapas relacionais. Os conflitos que envolvem a juventude não são marcados por adesões ou contraposições a utopias e ideologias sociais distantes. As questões emergentes dos jovens relacionam-se ao nascimento, à morte, à saúde, à sobrevivência imediata, ao prazer e ao divertimento e colocam em primeiro plano as relações com a natureza, a identidade sexual, os recursos comunicativos e a estrutura do seu agir individual. (CARRANO, 2005, p. 137).
\end{abstract}

À vista disso, para que o leitor adolescente possa construir identificação com o texto, este deveria partir dos pontos de interesse desta categoria - a juvenil. De acordo com Leahy-Dios (2005), de maneira generalizada, os principais interesses dos adolescentes têm sido o conhecimento do próprio corpo, as dificuldades nas relações familiares, sociais, afetivas, amorosas e sexuais.

Em Querida enfatizam-se as relações afetivas do protagonista Pollux com sua mãe. Pollux exige a presença constate da mãe e quanto mais o padrasto tenta 
conquistá-lo mais o garoto exige da mãe provas de amor. As histórias que este personagem inventa a cerca do padrasto o envolvem de tal maneira que até ele mesmo acredita serem reais: "Ele tem uma imaginação tão poderosa que ele mesmo acaba acreditando em tudo que inventa" (BOJUNGA, 2009, p. 99). Tanto Pollux como seu tio Pacífico revelam o sentimento de ciúme, nota-se isto na passagem a seguir em que a mãe do Pollux conversa ao telefone com Pacífico: “(...) E se você já está gostando do meu filho, nem que seja só um pouquinho, ajude ele a compreender que é o ciúme, e não o Roberto o inimigo que ele tem que vencer (...)" (BOJUNGA, 2009, p. 100).

É em torno de tal sentimento que a narrativa se desenvolve, atrelando ao texto as possibilidades da sociedade atual, e também, apresentando sentimentos universais, que ultrapassam as fronteiras do tempo. Por conseguinte, para comprovar a atemporalidade do assunto, destaca-se o trecho no qual a mãe de Pollux revela o ciúme que o Pacífico sentia:

(...) Eu era bem pequena quando você saiu lá de casa, mas nossos irmãos sempre me falam que você tinha um amor exagerado pela nossa mãe e nunca me perdoou a fatalidade dela ter morrido quando me deu a luz. Então, você deve saber, melhor que ninguém, o que o ciúme faz com a gente (...) (BOJUNGA, 2009, p. 99).

Os dois personagens, o adulto e o menino conhecem todo o sofrimento do ciúme, Bojunga (2009) apresenta através do diálogo entre ambos como esse sentimento é arrebatador e doentio:

(...) Ela falou que você também tinha um amor doente pela tua mãe (...) Eu nunca tinha pensado que o amor podia ficar doente (...) como é que a gente sabe quando ele adoece? (...) vai perdendo a alegria, vai deixando de se importar com os outros, fica só pensando na doença, acaba até ficando meio cansado de viver, o que, em outras palavras: significa: vontade de morrer.(BOJUNGA, 2009, p.155)

Nesse viés, Michèle Petit aponta para a importância da literatura no desenvolvimento social e psicológico do leitor adolescente:

Em especial na adolescência, a leitura pode ocupar um papel formador, capaz de mudar os rumos da vida e reorganizar os pontos de vistas, ao nos mostrar que estamos experimentando afetos, tensões e angústias universais. (PETIT, 2008, p. 50). reconheceu aquilo que sentia através do teatro que Ella encenou: 
(...) eu sempre achei que o nome que você escolheu pra mim não combinava comigo, sabe, pai; então pra este Pollux aqui (...) eu escolhi um nome que tem tudo a ver: CIÚME - gritou pra estrela. Ciúme - repetiu mais baixo, se virando pro Pollux. (...) (BOJUNGA, 2009, p. 125).

Conhecendo o que sentia, Pollux poderia admitir suas mentiras e aceitar o amor do padrasto, porque ele não queria ser aquela imagem feia que o ciúme revelou durante o teatro.

(...) Agora a cara dela era de uma velha-velhíssima, coberta de rugas e deformada por cicatrizes, manchas e feridas que o capuz do manto, puxado pra testa, não chegava a disfarçar. A figura entrou em cena curvada sobre uma bengala, arrastando um andar defeituoso para junto do Pollux. (...). (BOJUNGA, 2009, p. 123-124).

Considera-se assim que a encenação fora peça chave para que o personagem entendesse o quão prejudicial o ciúme era para si mesmo. Mostrando, desta forma, que a literatura ajuda o leitor a reconhecer-se construir a sua própria imagem, a partir daquilo que vivencia na leitura escrita ou na leitura de uma peça teatral.

Além disso, Bojunga (2009) constrói um protagonista leitor, que faz uso de fragmentos do poema de Gonçalves Dias para reconhecer e enfrentar aquilo que está sentindo no momento da fuga:

Não demorou nada pro medo chegar. E se ele fosse assaltado? Quem é que iria socorrer?(...) De coração sacudindo o peito, começou a recitar pensando os versos do Y Juca Pirama, que tinha decorado tempos atrás para recitar pro pai. Tu choraste em presença da morte?/Na presença de estranhos choraste?/Não descende o covarde do forte;/Pois, choraste, meu filho não és! (BOJUNGA, 2009, p. 32-33).

Sustentado pelo poder das palavras do Juca Pirama, Pollux é capaz de estabelecer correlações entre seus sentimentos e aquilo que é vivenciado no poema supracitado. É inegável que o leitor que se espera para esta obra consiga perceber as dificuldades do protagonista e, por outro lado, compreenda a participação da Arte na vida e nas resoluções dos problemas que tanto apavoram tal personagem.

Se de um lado a sociedade contemporânea se mostra líquida e pauta suas ações no consumo, no efêmero, por outro lado, os sentimentos universais ainda perduram, existem e persistem na busca do sentir-se e entender-se. A literatura, então se justifica para além do desespero: 
dividido e fragmentado, ainda é possível incorporar um senso de valor universal; e nos quais, em um mundo sordidamente material, ainda se pode vislumbrar um raro lampejo de transcendência. (EAGLETON apud LOTTERMANN, 2010, p. 13).

\section{CONCLUSÕES FINAIS}

Uma literatura de qualidade é aquela que o leitor pode sentir-se participante tal qual evidencia Eco (1994), quando explica que o leitor vai preenchendo aquilo que o texto não diz, mas espera do seu leitor a capacidade de apreender. Os diálogos e as escolhas na forma de narrar deixam, desta maneira as pistas que levariam o leitor em formação a construir sentido para o texto, despertando neste a capacidade de reflexão do mundo que o cerca.

O que o leitor, então, pode encontrar em Querida que sustente o selo de altamente recomendável? Querida apresenta, assim, uma narrativa em contato com seu público, espera-se desse leitor implícito conseguir compreender-se dentro do universo ficcional trazendo a narrativa para a sua vida, o seu meio social contemporâneo. Bojunga (2009) considera o seu leitor implícito alguém capaz de perceber que os seus personagens são subjetivos e que a essência deles pode ser adaptada a qualquer imagem física, sem obstruir o fluxo da narrativa.

Portanto, Querida apresentou uma narrativa que fornece amplas possibilidades de se ajustar aos aspectos do leitor juvenil atual e daquilo que se espera dele. Além disso, considerando que o leitor implícito de tal obra é um leitor em formação, Querida fornece subsídios para que este leitor consiga perceber as diferentes leituras que um texto literário pode oferecer. 


\title{
THE TEENNAGE READER IN QUERIDA
}

\begin{abstract}
Since 1974 the Fundação Nacional do Livro Infantil e Juvenil - FNLIJ choose the books that are worthy of the Highly Recommended Seal. The writer Lygia Bojunga has received the honor repeatedly. Her most recently awarded book was Querida, in 2010. This book was published in 2009. This paper seeks to identify in what extent Querida (2009) dialogues with the reader, considering it as directed to the age group of teenagers. In fact, in order to identify these aspects of dialogue (reader-book), this paper will consider literature as a symbolic and imaginative representation of social relations, using as approach the concepts and discussions promoted by the Sociology of Reading, as well as the reader-response criticism from what Querida assumes its model-reader, pointing out what he/she must be able to understand in order to fill the gaps in the text. Thus, this study also seeks to indicate the relevance of the sociocultural aspects imbricated in the construction of this model reader.
\end{abstract}

KEYWORDS: Querida. Reader. Lygia Bojunga. 


\section{REFERÊNCIAS}

BAUMAN, Zygmunt. Modernidade líquida. Rio de Janeiro: Jorge Zahar Ed., 2001.

BOJUNGA, Lygia. Querida. Rio de janeiro: Casa Lygia Bojunga. $1^{\circ} \mathrm{ed} .2009$.

COLOMER, Teresa. A formação do leitor literário: narrativa infantil e juvenil atual. Tradução Laura Sandroni. São Paulo: Global, 2003.

ECO, Humberto. Seis passeios pelos bosques da ficção. São Paulo: Companhia das letras, 1994.

HUNT, Peter. Crítica, teoria e literatura infantil. Tradução: Cid Knipel. Ed. rev. São Paulo: Cosac Naify, 2010.

JAMESON, Fredric. Pós-modernidade e sociedade de Consumo. Novos Estudos CEBRAP, São Paulo, n¹2, PP. 16-26, jun. 1985.

LEAHY-DIOS, Cyana. A educação literária de jovens leitores: motivos e desmotivos. In: RETTENMAIER, MIGUEL; RÖSING, Tania M. K; (Orgs.). Questões de literatura para jovens. Passo Fundo: Universitária, 2005. p.36-56.

LOTTERMANN, Clarice. Escrever para armazenar o tempo: morte e arte na obra de Lygia Bojunga. Cascavel: Edunioeste, 2010.

PETIT, Michèle. Os jovens e a leitura: uma nova perspectiva. Tradução Celina Olga de Souza. São Paulo: Editora 34, 2008.

CARRANO, Paulo César Rodrigues. Identidades juvenis e escola In: Construção coletiva: contribuições à educação de jovens e adultos. - Brasília: UNESCO, MEC, RAAAB, 2005. 
Recebido: 11 dez. 2016

Aprovado: 02 jun. 2017

DOI: 10.3895/rl.v19n24.5181

Como citar: JOHANN, Gisela. O leitor adolescente em Querida. R. Letras, Curitiba, v. 19, n. 24, p. 132-142,

mar. 2017. Disponível em: <https://periodicos.utfpr.edu.br/rl>. Acesso em: XXX.

Direito autoral: Este artigo está licenciado sob os termos da Licença Creative Commons-Atribuição 4.0 Internacional.

(c) (1) 